\title{
A hora da estrela e suas adaptações
}

\section{Cinema, televisão e literatura entre realismo e reflexividade}

\section{A hora da estrela and its adaptations}

\section{Cinema, television and literature between realism and reflexivity}

\section{Eduardo Miranda Silva}

Professor da Universidade Estácio de Sá e Doutor em Literatura, cultura e contemporaneidade (PUC-Rio). Universidade Estácio de Sá, Departamento de Cinema, Rio de Janeiro (RJ), Brasil.

\section{Recuo utópico e seus desdobramentos na cultura audiovisual}

Em tempos pós-utópicos de um Brasil recém-saído da ditadura militar, a cinematografia nacional da década de 1980 não experimentou a unidade de nenhum movimento estético e político, como ocorreu com o Cinema Novo nos dois decênios anteriores. Do ponto das ciências sociais, o campo das artes e da cultura se reorganizava depois de uma ressaca que destituiu o intelectual do papel de "tradutor de demandas sociais", conforme interpretou Marcelo Ridenti (2000, p. 52). O diagnóstico também teve correspondência na América Latina, como mostra a mensagem que a teórica argentina da literatura Beatriz Sarlo dirigiu aos intelectuais, refletindo talvez amargamente sobre sua própria condição de intelectual.

\footnotetext{
Pensaram que estavam na vanguarda da sociedade; que eram a voz dos que não tinham voz. Acharam que podiam representar os que viviam oprimidos pela pobreza e pela ignorância, sem saber quais eram seus verdadeiros interesses ou o caminho para alcançá-los. Pensaram que as ideias podiam descer até aqueles que, operários, camponeses, marginais, submersos num mundo cego, eram vítimas de sua experiência. Sentiram-se portadores de uma promessa: obter os direitos dos que não tinham direito algum. Pensaram que sabiam mais do que as pessoas comuns e que esse saber lhes outorgava um só privilégio: comunicá-lo e, se preciso fosse, impô-lo a maiorias cuja condição social as impedia de ver com clareza e, consequentemente, trabalhar no sentido de seus interesses. (SARLO, 2004, p. 159)
} 
Nesse sentido, chama a atenção que a diretora Suzana Amaral se tenha arriscado a reeditar, a despeito da crítica feita ao intelectual na produção cultural, o artista com papel social ao filmar a história de Macabéa, personagem alagoana do livro A hora da estrela, de Clarice Lispector. Outro passo ousado da cineasta foi a opção por deixar de fora do filme o narrador intradiegético Rodrigo S.M. A última obra de Lispector foi a sua primeira a retratar uma personagem de classe social diferente da sua. Simulando talvez a insegurança com a nova abordagem, a escritora delegou ao narrador a crise de consciência diante da tarefa e do poder de contar a história de Macabéa.

Ao se mascarar para dar voz a S.M., Clarice deixou de usar como pretexto para criar uma intimidade com sua personagem o fato de ter passado a infância entre Maceió e Recife ou de, coincidentemente, utilizar em seu ofício de autora de literatura uma máquina de escrever, mesma ferramenta de trabalho da datilógrafa Macabéa. Em entrevistas, a escritora chegou a contar que a diç̧ão do outro ela tentou apreender com visitas à Feira dos Nordestinos, em São Cristóvão, no Rio de Janeiro. O narrador da novela também guarda semelhanças parecidas tanto com a autora quanto com Macabéa. Nesse sentido, Rodrigo aproveita para interpelar o leitor, como se este duvidasse do que será narrado diante de tantas diferenças sociais entre ele e a personagem:

Como é que sei tudo o que vai se seguir e que ainda o desconheço, já que nunca o vivi? É que numa rua do Rio de Janeiro peguei no ar de relance o sentimento de perdição no rosto de uma moça nordestina. Sem falar que eu em menino me criei no Nordeste (LISPECTOR, 1977, p.12).

Enquanto adia o início da história, S.M. também apresenta ao leitor seus sacrifícios para se aproximar da vida que será narrada. É preciso, segundo ele, se alimentar frugalmente de frutas e beber vinho branco, "pois faz calor neste cubículo onde me tranquei e de onde tenho a veleidade de querer ver o mundo"; é preciso se abster de sexo e futebol, não fazer a barba durante dias, adquirir olheiras escuras, "vestir-me com roupa velha rasgada. Tudo isso para me pôr no nível da nordestina" (p. 20). O narrador crê, ainda, que esse rito de passagem o transformará em outra pessoa: "Voltarei algum dia à minha vida anterior? Duvido muito". Além das muitas inferências que S.M. faz até quase a metade do livro, antes que comece a narrar a história de Macabéa, ele deduz que sua desimportância como narrador é equivalente à de sua personagem como ser humano. Em caso de ser substituído por outro narrador, S.M. impõe, no entanto, uma condição: só um escritor do sexo masculino poderá contar a história da nordestina, "porque escritora mulher pode lacrimejar piegas". 
Assim, a opção estética de Suzana Amaral, de eliminar S.M. da trama, ao tomar A hora da estrela, de Lispector, como texto-base para seu filme, pode ser vista como um ato de subversão do travestismo literário de Clarice para Rodrigo em nome de um distanciamento masculino que supostamente estaria comprometido caso a narradora fosse uma mulher. Com a mudança, Amaral atenta para a complexa diegese cinematográfica, em que várias instâncias (luz, voz, música, interpretação dos atores) narram, em oposição à literatura, cujo único código é o da escrita. Mas, acima de tudo, reivindica a condição de grande narradora, solapando as vontades e a autonomia de Rodrigo S.M. Questionada sobre os motivos para a exclusão do narrador intradiegético e autorreferente, a diretora sintetizou a questão pelos problemas da metalinguagem no cinema, sem deixar, contudo, de evocar a clássica sentença de Gustave Flaubert quando de sua inquisição nos tribunais, acusado de ofensa à moral e à religião, sobre quem seria Madame Bovary (“Emma Bovary c'est moi", respondeu o escritor).

A metalinguagem não funciona. É apenas uma questão de linguagem fílmica. Os filmes que falam sobre filmes, histórias embrulhadas dentro de histórias, todas essas construções mise-en-abyme. Achei que tudo isso era muito complicado para o nosso público. As pessoas não entenderiam. Portanto, decidi contar a história diretamente, 'direto ao ponto', como se diz em inglês. Em outras palavras, eu eliminei o narrador porque, no meu entender, eu era o narrador. (ROSSBERG apud STAM, 2008: p.323)

Ao suprimir o modernismo do texto original em favor da apresentação da história em si, Amaral recusa a reflexividade para colocar Macabéa em destaque, indo "direto ao ponto". Em consequência disso, as opiniões de S.M. sobre a personagem que ele retrata são distribuídas nos diálogos da nordestina com outros personagens. Porém, segundo Robert Stam, a ausência de Rodrigo traz consequências, como, por exemplo, deixar o espectador menos consciente do universo burguês do narrador e mais imerso na história da trabalhadora de classe inferior. O teórico, que costuma abordar as interseções entre literatura e cinema, conclui que a escolha de Amaral pode ser vista como menos "elitista", uma vez que provoca em nós maior identificação com Macabéa, que está sem mediação intradiegética, ou seja, sem narração que tiraria o foco do tema principal: Macabéa. Por outro lado, essa falta de contemplação dos dois polos pelo espectador "suprime a realidade da classe na medida em que nos tornamos menos conscientes das diferenças sociais entre o narrador e a personagem", deslocando essas desigualdades para outro registro entre os próprios personagens - “onde o leque social é muito mais fechado” (STAM, 2008: p.326).

Assim sendo, num outro sentido o filme poderia ser visto como mais elitista, já que as reconhecidas diferenças sociais entre o personagem e o narrador são veiculadas de maneira pseudo-objetiva. A narração 'impessoal' do filme exibe a diferença social de Macabéa ao revelar que ela não consegue atender às normas 
burguesas de comportamento socialmente correto, normas que não precisam ser formuladas porque elas foram internalizadas pelo público de classe média que julga os personagens de acordo com elas. (Ibidem)

Algumas das reflexões de S.M. no romance de Lispector vêm corroborar a tese de Stam. Uma delas consiste na imaginação do narrador sobre o potencial de recepção da história que está prestes a contar. Sem a perspectiva de que sua literatura tenha alguma missão revolucionária, Rodrigo se coloca no papel de "válvula de escape e da vida massacrante da média burguesia": "se o leitor possui alguma riqueza e vida bem acomodada, sairá de si para ver como é às vezes o outro". O narrador também tem consciência da nulidade da penetração de sua história na classe sobre a qual escreve. "Se é pobre, não estará me lendo porque ler-me é supérfluo para quem tem uma leve fome permanente" (LISPECTOR, 1977, p. 30). Narradora substituta de Rodrigo S.M., Suzana Amaral, ao menos de maneira explícita no nível da trama, não reflete, por exemplo, sobre a condição do intelectual, como faz o narrador de Lispector: "Sou um homem que tem mais dinheiro do que os que passam fome (...) não tenho classe social, marginalizado que sou. A classe alta me tem como um monstro esquisito, a [classe] média com desconfiança de que eu possa desequilibrá-la, a classe baixa nunca vem a mim” (p. 19). Sobre a estética que será usada, S.M. também reflete, como se perguntasse antecipadamente ao seu interlocutor se há bom senso em suas escolhas (ao passo que, eliminando esse longo preâmbulo de making of, o filme de Amaral tem uma estética já dada e não questionada, se olharmos para a transposição da novela de uma perspectiva modernista):

Será que eu enriqueceria este relato se usasse alguns difíceis termos técnicos? Mas aí que está: esta história não tem nenhuma técnica (...) Eu que também não mancharia por nada deste mundo com palavras brilhantes e falsas uma vida parca como a da datilógrafa (Ibidem: p.36).

Como contraponto às desvantagens - essas que apontamos acima - assumidas por Amaral ao retirar do texto fílmico a autorreflexividade, a narradora se dá ao luxo de proporcionar a Macabéa o que Rodrigo diz ser impossível, longe de seu alcance, "dar-lhe um bom banho, um prato de sopa quente, um beijo na testa enquanto a cobria com um cobertor (...), fazer que quando ela acordasse encontrasse simplesmente o grande luxo de viver". Assim, diferentemente do desfecho programado para Macabéa na novela de Clarice (a morte), a cena final do filme é um corte de passagem do atropelamento para o encontro apoteótico entre a personagem e o homem loiro anunciado pela cartomante. Esse gesto recupera, se não intradiegeticamente, o poder de Amaral ao menos como a grande narradora da história. O congelamento da imagem de uma Macabéa que ganhou "um bom banho" e encontrou "o grande luxo de viver" como plano último do filme é a recusa da cineasta em aceitar as fatalidades do destino. A opção 
de Suzana Amaral reafirma, na estética realista, seu papel de intelectual, quando se recusa a também morrer. Pois, em seguida à morte de Macabéa, assistimos, na novela de Lispector, à morte simbólica do narrador. "Macabéa me matou (...) Não vos assusteis, morrer é um instante, passa logo, eu sei porque acabo de morrer com a moça", constata Rodrigo S.M. (p. 86).

\section{Metalinguagem como desmistificação ou domesticação?}

A vida e a morte de Macabéa como invenção literária nas mãos do narrador são retomadas no programa Cena Aberta. Exibida em quatro episódios, no ano de 2003, na TV Globo, a atração foi concebida pelos cineastas Jorge Furtado e Guel Arraes e teve a apresentadora e atriz Regina Casé travestida ora em Rodrigo S.M., ora em grande narradora ${ }^{1}$, ora no papel da cartomante, ora na personagem Glória, amiga da protagonista da novela de Clarice Lispector. Interessa-nos, sobretudo, o papel de Casé no lugar de S.M. À maneira de um grande making of, que é ao que o programa se propõe, os fatos em Cena Aberta podem ser narrados, mas também podem retroceder no tempo. Roteirista da trama, Furtado explicita dualidades que ganham força e importância na linguagem do audiovisual, como as diferenças entre o contar e o mostrar, bem como as implicações contidas em cada uma dessas categorias. Assim, Regina Casé, a quem vamos nos referir como narradora, lê o trecho da obra de Lispector em que Macabéa morre, mas interpreta, como atriz que é, uma rejeição à encenação da morte. "Agora que a gente já contou que ela morre, quem sabe a gente não pode parar a história ali pelo meio, com um final mais alegre?", propõe Casé, já no início do programa. Seu poder sobre a narrativa visa extrapolar mesmo a estratégia modernista da autorreflexividade, ao confundir sua função dentro da história e a função de palavras de ordem que poderiam ser dadas tanto no nível do enredo (como personagem) quanto no nível da linguagem (como narradora). Assim, no papel da cartomante, ao vislumbrar apenas tragédias no passado e no presente de Macabéa, Casé ordena "corta!", como se pedisse novamente para que a cena fosse interrompida. A ambiguidade está no fato de que, como ocorre na obra literária, a expressão "corta" é um pedido da

${ }^{1}$ O conceito de "grande imagista" é de Albert Laffay (Logique du cinéma, 1964) e será retomado e explicado por André Gaudreault e François Jost em A narrativa cinematográfica (2009). Segundo estes, as diversas instâncias narrativas do cinema, para além do que há na diegese, tornam o que o espectador vê algo menos simples que a "mostração". Gaudreault e Jost lembram, ainda, das diversas denominações dadas a essa particularidade cinematográfica - "narrador invisível" para RoparsWuilleumier (1972), "enunciador" para Casetti e Gardies (1983; 1988), "narrador implícito" para Jost (1988) ou, ainda, "meganarrador" para Gaudreault (1988), Eis o conceito: "No decorrer dos eventos que formam a trama narrativa, os atores de cinema, ao contrário dos de teatro, não são, então, os únicos a emitir 'sinais'. Esses outros sinais, que vêm pelo viés da câmera, são plausivelmente emitidos por uma instância situada de algum modo acima dessas instâncias de primeiro nível que são os atores; por uma instância superior, portanto, que seria o equivalente cinematográfico do narrador escritural" (GAUDREAULT; JOST, 2009, p. 41). 


\section{ALCEU}

ISSN: $2175-7402$

cartomante para que Macabéa separe as cartas do baralho a fim de que a vidente inicie a leitura do seu futuro. No nível narrativo, porém, a apresentadora poderia estar ordenando a retirada dos elementos trágicos da história.

A intenção de borrar as fronteiras entre elementos que estão no eixo da trama e outros que estão no eixo da linguagem reverbera, também, na tentativa de embaralhamento entre a fiç̧ão e a realidade. Já de início, a apresentadora explica que o programa vai escolher uma Macabéa entre as várias Macabéas do mundo real. Em seguida a esse esclarecimento das regras do jogo, vemos uma fila de moças na faixa dos 19 anos de idade que aguardam para fazer o teste de elenco, o making of do making of, a narrativa em abismo da televisão, bem característica de programas como Vídeo Show, exibido por décadas na mesma emissora, ou atrações humorísticas que parodiam, no mesmo canal, as personalidades que já estão interpretando. Conforme a crítica de Robert Stam (2006, p. 176), "na era pós-modernista contemporânea, a reflexividade é a norma, não a exceção", o que leva o teórico a concluir que a reflexividade não vem equipada com uma valência política a priori, ela pode ser utilizada "pelo esteticismo da arte pela arte, pelo formalismo específico de cada meio, pela publicidade ou pelo materialismo dialético", pode ser narcisista ou intersubjetiva, "signo de uma urgência politicamente motivada ou de uma lassidão niilista". Também o crítico Jean-Claude Bernardet relativiza estes pressupostos estético-narrativos da reflexividade e aponta para uma tendência do cinema brasileiro, desde os anos 1960, para uma "doença infantil da metalinguagem", embora reconheça que outros filmes possam obter uma dimensão mais complexa por meio do recurso ${ }^{2}$. Em vídeo gravado posteriormente sobre o processo criativo do programa ${ }^{3}$, o diretor Jorge Furtado reforça em seu depoimento a clara intenção de borrar as fronteiras entre ficção e realidade. "Assistindo ao programa hoje, eu tenho dificuldades de identificar o que é texto da Clarice Lispector e o que é texto delas (as nordestinas que foram colocadas em cena no programa). É impressionante como a Clarice conseguiu capturar a fala dessas mulheres", afirma o diretor.

Muito "fiel" na leitura literal do texto de Lispector e em algumas das propostas da escritora, Cena Aberta repete a estratégia de retardar a identificação de sua personagem. Rodrigo S.M. revela o nome de Macabéa apenas na página 43, já na segunda metade da novela. Atento à linguagem do audiovisual, Jorge Furtado adia não o nome, mas a imagem do rosto da moça que viverá Macabéa. Casé utiliza os mesmos

\footnotetext{
${ }^{2}$ Entrevista disponível em < https://cultura.estadao.com.br/noticias/geral,o-critico-de-cinema-bernardet-e-homenageado-aos70-anos,7631>

${ }^{3}$ Disponível em <https://www.youtube.com/watch?v=wSBCdNsYvLc>
} 
argumentos que S.M. para justificar esse atraso. A candidata eleita só é revelada aos 30 minutos de um programa que tem menos de uma hora de duração. Para ambos os narradores, "como essa nordestina, há milhares de moças espalhadas por cortiços, vagas de camas num quarto, atrás de balcões, trabalhando até a estafa. Não notam sequer que são facilmente substituíveis". Com isso, o programa de televisão, ao adiar a escolha do rosto de Macabéa, dá um provisório protagonismo a todas as moças que estão no palco para disputarem o papel da personagem. "A gente quer contar essa história todo mundo junto, eu de Macabéa, vocês de Macabéa, todo mundo aqui já é um pouco Macabéa", diz a apresentadora, dirigindo-se às candidatas.

Novamente, a autorreferência da televisão e sua linguagem de retroalimentação são postas em destaque. Com a "deixa" de que ela também pode ser a protagonista, Regina Casé, já ciente de que seu poder de comunicação com o público popular decorre de sua "cara de pobre", pergunta, retoricamente, se as candidatas conhecem alguma artista com cara de nordestina. Como reação, o riso das moças, que Casé simula não entender. A associação entre nordestino e cara de pobre é feita pela própria apresentadora. “Eu [tenho cara de nordestina]?!?”, finge espanto e complementa, já em tom explicativo: "É que hoje em dia eu sou conhecida, mas eu continuo igual, com cara de pobre, mão de pobre, pé de pobre. Meu avô veio [para o sudeste] de pau-de-arara". Casé propõe um jogo: "desmascarar" as candidatas que não são nordestinas e que se vestiram, segundo estereótipos, como tal. No palco, ela pergunta a uma candidata nordestina se ela vestiu jeans e uma blusa estilo top para ficar com o visual mais moderno: "Você acha que lá no Ceará as pessoas usam isso?", instaura a dúvida, remetendo as candidatas e o espectador tanto a um imaginário popular quanto a um imaginário que pode ser produto das representações que a Globo faz do Nordeste em sua teledramaturgia. Regina pede que as meninas troquem o figurino e desafia a nordestina, agora "com roupa de nordestina", a dizer na frente das demais: "Eu sou carioca!". Pouco convencida, a moça repete a afirmativa. E a apresentadora retruca, em tom de brincadeira: “É naaada!", provocando gargalhada generalizada entre as candidatas a Macabéa. A reflexividade narcisista da qual fala Stam é novamente exercitada por Regina Casé, que faz julgamentos tendo como referência celebridades da TV Globo, ainda que no intuito de desestabilizar os estereótipos. "A Xuxa não tem a menor cara de nordestina, nem a Angélica. E a Carolina Dieckmann? Não tem a menor cara de nordestina também”.

A proposta de construir a personagem a partir da vida real das candidatas segue até o fim como ponto forte. À candidata escolhida para viver Macabéa, Regina pergunta quais são as características das 
demais meninas nordestinas que ela utilizará para compor essa Macabéa coletiva. Em paralelo à ficção dentro da ficção que vai sendo construída (a história de Macabéa), Cena Aberta destaca a semelhança entre as histórias de vida das moças e a da protagonista. Em depoimentos reais, as candidatas - que já não são candidatas, mas entraram, de alguma outra forma, na tessitura da trama - contam por que motivos vieram parar no Rio de Janeiro.

Outro tema que aparece nesses depoimentos é a noção de felicidade. A consciência sobre o que significa o estado de felicidade coloca, novamente, essas personagens como sujeitos de suas próprias histórias, se lembrarmos que Macabéa sequer tinha noção sobre o que significava ser feliz. 0 protagonismo de Macabéa, representado pela concessão de voz às candidatas-atrizes, é recuperado, também, com a convocação de Regina Casé para que as meninas, Macabéas da história, ajudem a compor o figurino da personagem Glória. Nas palavras de Lispector, Glória se sobressaía por ser "pertencente ao ambicionado clã do sul do país". A simplória escolha do figurino da carioca pela "nortista" revela a inversão da perspectiva normatizada, que é, tanto no filme quanto no romance, a de Glória sempre olhando e criticando a aparência e as maneiras de Macabéa, uma noção perversa entre sujeito e objeto.

Para além de questões metalinguísticas levantadas aqui, que aproximam Cena Aberta da novela de Clarice Lispector, o programa guarda semelhança estrutural com o filme de Suzana Amaral. Em ambos, o narrador S.M. foi extirpado. À sua maneira, Regina Casé preenche esse lugar, materializando-se na imagem como metanarradora. Sua aparição é tão ampliada quanto a das vozes periféricas do discurso, em razão, inclusive, da ambição do programa de se abrir ao real das "milhares de Macabéas". Seu ato final como mestre de cena é impedir, mais uma vez, agora em chave metalinguística, a morte de Macabéa. Na cena derradeira, Casé substitui a Macabéa atriz pela dublê, que será atropelada por um carro. Assim, ela salva a protagonista, que ganha liberdade para sair da cena, caminhando para fora do quadro ao lado de Olímpico, enquanto o fatídico acidente é gravado no centro do quadro.

Já a Suzana Amaral cabe o papel de grande narradora, de mostradora de imagens que orquestram um outro tipo de realismo, mais filiado à tradição do romance do século XIX que à modernidade literária de Lispector. E, embora nossos apontamentos sobre o filme de Amaral pareçam partir de um paradigma modernista - o de reconhecer na transposição para as telas a ausência do narrador autorreflexivo da novela de Lispector -, o objetivo não é o de valorar as estéticas. Por isso, feitas as considerações acerca da autocrítica no próprio tecido narrativo, o movimento de conclusão dessa análise vai em direção à 
reabilitação do potencial político contido na estética realista, mais próxima da versão cinematográfica de $A$ hora da estrela. Há que se lembrar do exemplo da chegada do cinema em cores, seguido por várias gerações de espectadores que continuaram a ver o filme em preto-e-branco como mais "realista" que o filme colorido ${ }^{4}$. Curiosamente, a película colorida estava mais próxima ao que o olho humano captura fora de uma sala de cinema, no chamado "mundo real", e deveria ser, assim, mais "realista".

\section{Realismo do comum}

Movimentos estéticos do cinema que se apresentaram como alternativa ao realismo mais conservador (transparente em sua edição, de modo que a perfeita sutura ${ }^{5}$ da película à la Hollywood revelasse um mundo nas telas, e não uma artificialidade que deixava a linguagem opaca, justamente para mostrar que era opaca frente ao mundo real) não prescindiram do realismo. Alguns deles o tiveram como referência: é o caso do surrealismo, do neorrealismo, do realismo poético ou do realismo psicológico. Por outro lado, há, ainda, o fato de que a teoria fílmica da década de 1970 "costumava ver a reflexividade como uma panaceia política, enquanto deixava de notar o potencial progressista do realismo" (STAM, 2008, p.31). Os impasses sobre o tal potencial da estética realista são grandes e encontram na política da autorreflexividade um obstáculo para que seja considerada progressista.

No cinema, o caráter da reflexividade ocorre pelo chamamento à ação do espectador (na proposta e leitura de Sergei Eisenstein segundo alguns cineastas e filmes do Cinema Novo) e, posteriormente, em outra chave, como mea culpa em relação à montagem invisível ou a um "narrador invisível" (ROPARSWUILLEUMIER, 1972 apud GAUDREAULT; JOST, 2009), de terceira pessoa, com a criticada "voz de deus". Nesse segundo aspecto, a resposta à "voz sociológica" do cinema veio, sobretudo, com o documentarista

\footnotetext{
${ }^{4}$ Em A Imagem, Jacques Aumont (2002) retoma algumas considerações feitas pelo crítico de arte Ernest $\mathrm{H}$. Gombrich, em Arte $e$ ilusão, para quem o realismo é uma convenção que passa por atualizações na História. Esse realismo está mais ligado a convenções sobre o que se entende como real em cada época do que propriamente pela relação que se estabelece entre a produção da imagem e a noção de realidade.

${ }^{5}$ Jean-Pierre Oudart (1969) toma emprestada a perspectiva lacaniana da relação que se estabelece entre o sujeito e seu discurso para o cinema, entendendo como "sutura" a articulação que se estabelece entre os planos cinematográficos e o sujeito espectador, ou mesmo da completude que o presente realiza com o ausente, com a "falta", como, por exemplo, o que está no campo e o que está fora-de-campo, ou "campo ausente". Jacques Aumont e Michel Marie explicam que o conceito acabou sendo banalizado no momento em que outros teóricos o estenderam a todas as espécies de raccord de olhar (AUMONT; MARIE, 2003 , p. 82). Aqui, utilizamos "sutura" como a montagem transparente em oposição à montagem opaca, conceitos debatidos por Ismail Xavier em $O$ discurso cinematográfico: a opacidade e a transparência.
} 
Eduardo Coutinho 6 . Seu filme Cabra marcado para morrer é emblemático dessa "virada antropológica" que fez ascender novas vozes do discurso. Quando retoma em 1984 o filme iniciado em 1964 e interrompido por razões ligadas à censura, Coutinho apresenta o material aos personagens das Ligas Camponesas e não só ouve críticas ao filme, como também as contempla no produto final exibido ao espectador e ainda se coloca, na figura de cineasta e mestre de cerimônias, no filmado. Ismail Xavier, com Sertão Mar e Alegorias do subdesenvolvimento, e Jean-Claude Bernardet, com Brasil em tempo de cinema e Cineastas e imagens do povo, são dois teóricos dedicados a uma historiografia do cinema nacional que compreenda os aspectos da opacidade narrativa cinemanovista e autocrítica que viria em seguida de cineastas do próprio Cinema Novo pela linguagem por vezes hermética, bem como do CPC da UNE (Centro Popular de Cultura da União Nacional dos Estudantes), pela linguagem excessivamente didática e ao qual Eduardo Coutinho esteve inicialmente filiado.

Em seu artigo $O$ Efeito de realidade e a política da fiçcão, Jacques Rancière sai em defesa da abertura ao social proporcionada pelo romance realista. $O$ filósofo lê o clássico texto de Roland Barthes $O$ efeito de realidade à luz da crítica contemporânea de autores como Gustave Flaubert. Para esses críticos literários, o "excesso descritivo" elevou "o custo da informação narrativa", nas palavras de Barthes. Rancière vai de encontro a essa tese e avança em sua percepção acerca de autores como Dostoievski e Stendhal em nome de uma "inversão da lógica hierárquica do regime representativo". Para o autor, o efeito de realidade, o excesso descritivo - visto de modo negativo pela crítica conservadora, que buscou um romance de estrutura definida, com cabeça, tronco e membros - é um efeito de igualdade. A igualdade da qual nos fala Rancière (2010, p.79) "não significa somente a equivalência entre todos os objetos e sentimentos descritos pelo romancista", também não significa "que todas as sensações são equivalentes, mas que qualquer sensação pode produzir em qualquer mulher pertencente às 'classes mais baixas' uma aceleração vertiginosa, fazendo-a experimentar as profundezas da paixão".

\footnotetext{
${ }^{6}$ Bernardet, em Cineastas e imagens do povo, faz uma série de ressalvas ao documentário sociológico, que coloca em relevo a "voz de deus" de um narrador em estúdio. Segundo ele, essa instância sonora do filme subjuga a força das imagens do povo e a coloca a serviço de uma voz que atende aos anseios do diretor e da tese sociológica que ele quer provar sobre esse mesmo povo, sobre a nação e sobre aspectos de uma macrohistória. Vale cotejar as considerações de Bernardet com o contraponto apresentado por Fernão Pessoa Ramos (2008), em Mas afinal... o que é mesmo documentário?. Para Ramos, a questão ideológica está presente, mas ela tem como corresponsável por esse tipo de filme sociológico a limitação técnica da época, ou seja, a impossibilidade de levar às ruas câmeras leves e gravadores sonoros acoplados que pudessem capturar de forma sincrônica os dois principais elementos que compõem um filme: a imagem e o som.
} 
Ainda que esta exposição sobre o potencial político do realismo não invalide a necessidade de autocrítica do intelectual, gesto muito bem realizado por Clarice Lispector por meio de seu narrador, Rodrigo S.M., e retrabalhado no seriado Cena Aberta como metalinguagem lúdica, a descrição realista de detalhes da vida de Macabéa, no filme de Suzana Amaral, deixa entrever, ainda nas palavras de Rancière, algo proporcionado pelo cinema, que vem a ser "uma forma de comunismo" que oferece "a utopia de um mundo espontaneamente comunista por construir uma percepção comum" (p. 89).

Nas últimas décadas, acompanhamos às narrativas filiadas a um modernismo que militou pela descoberta dos procedimentos da ficção. Em um eixo mais específico, a partir dos anos 70, a autoficção funcionou ideologicamente como possibilidade de recuo do autor, acompanhada de um conforto por não se ver mais diante da necessidade de falar sobre e pelo outro, mas, agora, de si mesmo. Vimos surgir ainda, mesmo no âmbito da ficção, a ascensão do relato testemunhal, modelo que já vem apresentando certo esgotamento. Em sua obra mais recente, o crítico de arte e historiador estadunidense Hal Foster (2021, p. 176) sinaliza, no artigo "Fiç̧ões reais", a mudança de uma política da testemunha, fundada no depoimento individual, em direção a uma política de defesa de direitos humanos, reabilitando, de alguma forma, o papel da ficção. Assim, podemos inferir que, mais que propor narrativas em abismo, ou seja, narrativas que se desdobram e que pretendem dar conta do desvelamento de procedimentos internos do narrar ou de histórias que só podem ser legitimadas quando há semelhanças entre a voz do autor, do narrador e intimidade com o narrado, o potencial da ficção está também na capacidade de deslocamento do autor em direção a alteridades no discurso e na recepção da obra.

Eduardo Miranda Silva

ORCID: https://orcid.org/0000-0003-0146-4213 Universidade Estácio de Sá, Departamento de Cinema, Rio de Janeiro (RJ), Brasil. Doutor em Literatura, cultura e contemporaneidade / PUC-Rio E-mail: edumirando@gmail.com

Recebido em: 3 de junho de 2020.

Aprovado em: 15 de julho de 2020. 


\section{Referências:}

AUMONT, J. A Imagem. Campinas, SP: Papirus, 2002.

; MARIE, M. Dicionário teórico e crítico de cinema. Campinas, SP: Papirus, 2003.

BERNARDET, Jean-Claude. Cineastas e imagens do povo. São Paulo: Companhia das Letras, 2003.

Brasil em tempo de cinema: ensaio sobre o cinema brasileiro de 1958 a 1966. São Paulo: Companhia das letras, 2007.

LISPECTOR, Clarice. A hora da estrela. Rio de Janeiro: Nova fronteira, 1977.

RANCIÈRE, Jacques. O efeito de realidade e a política da ficção. Novos estudos - CEBRAP [online]. 2010, n.86, pp. 75-80. ISSN 0101-3300.

RIDENTI, Marcelo. Em busca do povo brasileiro: artistas da revolução, do CPC à era da tv. Rio de Janeiro: Record, 2000.

SARLO, Beatriz. Cenas da vida pós-moderna: intelectuais, arte e vídeo-cultura na Argentina. Rio de Janeiro: UFRJ, 2004.

Tempo passado: cultura da memória e guinada subjetiva. São Paulo: Companhia das Letras; Belo Horizonte: UFMG, 2007.

STAM, Robert. O espetáculo interrompido: literatura e cinema de desmistificação. Rio de Janeiro: Paz e Terra, 1981.

2008.

A literatura através do cinema: realismo, magia e a arte da adaptação. Belo Horizonte: UFMG,

XAVIER, Ismail. O discurso cinematográfico: a opacidade e a transparência. São Paulo: Paz e Terra, 2005.

\section{Resumo}

Tendo como ponto de partida as reflexões de Rodrigo S.M. no romance A Hora da Estrela, de Clarice Lispector, o artigo se propõe a discutir algumas das opções narrativas em duas adaptações audiovisuais da obra literária. Na primeira obra, o filme homônimo A Hora da Estrela, de 1985, a diretora Suzana Amaral opta por focalizar apenas a história de Macabéa, deixando de fora as elucubrações de um narrador culpado. Em um segundo momento, o programa de televisão Cena 
Aberta, de 2003, do diretor e roteirista Jorge Furtado, ajusta seu foco justamente na problemática de se falar pelo outro de classe. Nossa hipótese inicial sugere uma dificuldade do cinema de destituir o intelectual tradicional de seu poder de narrar, no caso do filme de Suzana Amaral. Mas também aponta para a perda do outrora poder de choque a qual a metalinguagem se propunha. Essa mesma metalinguagem é o instrumento primeiro de fatura utilizado por Jorge Furtado na adaptação de Lispector para o programa da TV Globo.

Palavras-chave: Cinema. Televisão. Literatura. Realismo. Metaficção.

\section{Abstract}

Starting from Rodrigo S.M.'s reflections in the novel A Hora da Estrela, by Clarice Lispector, the article aims to discuss some of the narrative options in two audiovisual adaptations of the literary work. In the first work, the homonymous film A Hora da Estrela, from 1985, director Suzana Amaral chooses to focus only on the story of Macabéa, leaving out the elocobracoes of a guilty narrator. In a second moment, the 2003 Cena Aberta television program, by director and screenwriter Jorge Furtado, adjusts its focus precisely to the problem of speaking for the other class. Our initial hypothesis suggests a difficulty for cinema to deprive the traditional intellectual of his power to narrate, in the case of Suzana Amaral's film. But it also points to the loss of the former shock power that metalanguage proposed. This same metalanguage is the first invoice instrument used by Jorge Furtado in the adaptation of Lispector for the TV Globo program.

Keywords: Cinema. Television. Literature. Realism. Metafiction.

\section{Resumen}

A partir de las reflexiones de Rodrigo S.M. en la novela A Hora da Estrela, de Clarice Lispector, el artículo tiene como objetivo discutir algunas de las opciones narrativas en dos adaptaciones audiovisuales de la obra literaria. En el primer trabajo, la película homónima A Hora da Estrela, de 1985, la directora Suzana Amaral opta por centrarse solo en la historia de Macabéa, dejando de lado los elocobracos de un narrador culpable. En un segundo momento, el programa de televisión de 2003 Cena Aberta, del director y guionista Jorge Furtado, se enfoca en el problema de hablar por la otra clase. Nuestra hipótesis inicial sugiere una dificultad para el cine al privar al intelectual 
tradicional de su poder de narrar, en el caso de la película de Suzana Amaral. Pero también apunta a la pérdida del poder una vez impactante que propuso el metalenguaje. Este mismo metalenguaje es el primer instrumento de factura utilizado por Jorge Furtado en la adaptación de Lispector para el programa TV Globo.

Palabras clave: Cinema. Televisión. Literatura. Realismo. Metaficción.

Este artigo é publicado em acesso aberto (Open Access) sob a licença Creative Commons Attribution Non-Commercial (CC-BY-NC 4.0), que permite que outros remixem, adaptem e criem a partir do seu trabalho para fins não comerciais, e embora os novos trabalhos tenham de lhe atribuir o devido crédito e não possam ser usados para fins comerciais, os usuários não têm de licenciar esses trabalhos derivados sob os mesmos termos. 